\title{
COMPLEXIDADE, CURRÍCULO E ÉTICA: O PARTO DE UM NOVO MUNDO
}

\author{
Complexity, curriculum, and ethics: the delivery \\ of a new world
}

\author{
Ricardo Tescarolo ${ }^{1}$ \\ Kelley Cristine Gonçalves Dias Gasque ${ }^{2}$
}

\section{Resumo}

Este artigo analisa a crise do pensamento ocidental contemporâneo e a emergência de uma nova cosmologia fundada na complexidade. Ela representa a superação da visão que pretendeu descobrir princípios de simplicidade, estabilidade e objetividade em uma realidade essencialmente complexa e ambígua. A superação da concepção fragmentadora da realidade encontrase no centro dessa nova visão, conciliando reflexão com sensibilidade e razão com experiência. Da idéia de complexidade resulta uma ética que constitui o fundamento do reconhecimento de que a dimensão interior de cada mulher e homem o/a transforma em um acontecimento de importância cósmica. E dela resulta também a urgência de que todas as instâncias da sociedade - mas principalmente a escola, por sua própria raison dêtre - assumam a sua responsabilidade social e planetária, estabelecendo um novo contrato de solidariedade em favor da Terra, da Vida e da Humanidade.

Palavras-chave: Complexidade; Currículo escolar; Ética.

Doutor em Educação pela USP; professor do programa de pós-graduação stricto sensu em Educação da PUCPR. e-mail: rtescarolo@pucpr.br

2 Doutoranda e Mestre em Ciência da Informação pela UnB, especialista em Literatura Brasileira pela Universidade Católica de Brasília. Assessora dos núcleos Tecnologia da Informação e Psicopedagógico do Colégio Marista de Brasília. e-mail: kelley@unb.br; kdias@marista.org.br 


\section{Abstract}

This article analyses the crisis of the contemporary western mind and the emergence of a new cosmology based upon the complexity. It represents the overcoming of a vision that intended to discover the principles of simplicity, stability, and objectivity in an essentially complex and ambiguous reality. This overcoming of a reduced-to-pieces reality occupies the heart of this new vision, conciliating reflexive thinking with sensibility, and reason with experience. From the idea of complexity results an ethics that constitutes the foundation of the recognition that the inner dimension of every man and woman transforms him/her in a event of cosmic importance. And from this very idea also results the urgency of which every instance of human societybut especially the school, because of its very raison d'être - shoulders the social and planetary responsibility, establishing a new contract in behalf of the Earth, the Life, and the Humanity.

Keywords: Complexity; Curriculum; Ethics.

\section{Introdução}

O pensamento ocidental masculino, guiado por "um impulso heróico de forjar o ser humano racional e autônomo", separou-o de sua "unidade primordial" e negou a anima mundi, "a comunidade do ser, o onipresente, o mistério e a ambigüidade, a imaginação, a criatividade, emoção, instinto, Natureza, mulher". Na esteira dessa crise, a humanidade vive "um anseio de re-união". Esse desejo intenso vem impelindo o espírito humano a "se re-ligar com a essência de seu ser", o que o instiga a "produzir algo fundamentalmente novo na história humana: é como se estivéssemos testemunhando, sofrendo o parto de uma nova realidade" (TARNAS, 2005, p. 471).

Nesse contexto, observamos a agonia da concepção determinista, linear e homogênea da história do pensamento e a emergência de uma "consciência crescente de descontinuidade, de não-linearidade, da diferença", que implica "uma reordenação intelectual que nos habilite a pensar" a complexidade essencial dos problemas contemporâneos (SCHNITMAN et al., 1996, p. 16-17).

A re-união do que foi desarticulado só poderá ser plenamente atingida, porém, se for promovida "uma revisão da idéia de natureza", como propõe Hans Jonas (2004, p. 272): "a natureza no vir-a-ser, mais do que a natureza no permanecer". Dessa nova idéia resulta um princípio ético que assume como fundamento "uma atribuição objetiva por parte da natureza do todo" e no reconhecimento de que a dimensão interior do ser humano "pode fazer dele um acontecimento de importância cósmica”. Por conseguinte, apenas a ética fundada na plenitude do ser terá de fato importância "no universo das coisas" (JONAS, 2004, p. 272). 
Para entender e explicar essa realidade progressivamente complexa do mundo contemporâneo e superar os modelos científicos herdados do racionalismo cartesiano e do positivismo comteano, foram realizados estudos flexíveis denominados 'teorias da complexidade', um sistema inédito de referências epistemológicas e ontológicas que resultaram em uma nova forma de questionamento da realidade e uma categoria fundante do paradigma emergente.

\section{A emergência da complexidade e suas circunstâncias}

Como fenômeno intrinsecamente ambíguo e ambivalente, o paradigma da complexidade resulta da superação da visão que pretendeu descobrir os princípios da simplicidade, estabilidade e objetividade da realidade. O primeiro princípio diz respeito à crença em que a separação do mundo complexo em partes é necessária para se entender o todo. O segundo se vincula à idéia de que o mundo é estável e que os fenômenos são previsíveis e controláveis. E o terceiro se baseia na confiança de que é possível conhecer o mundo objetivamente, colocando-se entre parênteses a subjetividade do pesquisador (VASCONCELLOS, 2003). Todavia, essa nova perspectiva constitui mais um desafio e um problema do que uma resposta, como bem o coloca Morin (1995), e os princípios que o sustentam surgem do questionamento dos princípios da determinação, da separação, da redução e da validade absoluta da lógica clássica da modernidade.

A superação da concepção da fragmentação da realidade encontra-se no centro da cosmologia emergente e sustenta-se na idéia de que "o mesmo ciclo da vida que aparece na sociedade humana e que constitui a sua própria essência aparece também na natureza" (CASSIRER, 1976, p. 57).

A complexidade se manifesta na simbiose cheia de energia, inextricável e delicada da Noosfera, a esfera reflexiva (humana) da Terra, com a Biosfera, a camada viva não reflexiva que alimenta e sustenta a Noosfera, que por sua vez depende de sua preservação (CHARDIN, 1986, p. 210). Ora, esse desejo (e a necessidade) de re-ligação deve ocorrer também no pensamento científico, como sugere Foucault (2004, p. 339), pois não se pode conhecer a si mesmo como convém senão sob a condição que se tenha sobre a natureza um ponto de vista, um conhecimento, um saber amplo e detalhado. [...] Conhecimento de si e conhecimento da natureza não estão, portanto, em posição de alternativa, mas absolutamente ligados.

Essa anunciada matriz epistemológica entende o mundo como "um evento emergente que envolve uma abertura ao novo e ao inesperado" e as pesquisas científicas como diálogos, "e não monólogos que podem ser sustentados unilateralmente" (SCHNITMAN; LITTLEJOHN, 1999, p. 23). 
Por conseguinte,

as novas condições contemporâneas propõem cenários alternativos de fluxos, incluem o emergente, o viver e o administrar um processo de mudança permanente, a surpresa de explorar o ainda desconhecido e descobrir a efetividade do que está se formando, o surgimento de possibilidades, incluindo a possibilidade de trabalhar e construir na incerteza (SCHNITMAN; LITTLEJOHN, 1999, p. 22).

Em uma conferência na Universidade de Santa Kilda, Austrália ${ }^{3}$, Maturana postulou a complexidade das realidades não como um fenômeno absoluto e exclusivamente objetivo, mas que existe dependentemente das pessoas e do mundo, de tal maneira que é quase impossível, por exemplo, distinguir percepção de ilusão (no sentido de experiência válida em um determinado domínio, mas percebido em outro), bem como aceitar a idéia paradoxal de "uma total separação entre o observador e uma realidade suposta completamente independente desse observador" (MATURANA apud NICOLESCU, 1999).

Nesse sentido, Maturana e Varela advertem-nos que:

A suposição de um mundo objetivo, independente de nós como observadores e acessível ao nosso conhecimento por meio de nosso sistema nervoso, não permite entender como este funciona em sua dinâmica estrutural, pois exige que o meio especifique seu operar. Mas, se não afirmamos a objetividade do mundo, parece que estamos propondo que tudo é pura relatividade, que tudo é possivel, que negamos toda legalidade. [...] Na verdade, todo mecanismo de geração de nós próprios como agentes de descrições e observações nos explica que nosso mundo, bem como o mundo que produzimos em nosso ser com outros, sempre será precisamente essa mescla de regularidade e mutabilidade, essa combinação de solidez e de areias movediças, tão própria da experiência humana quando examinada de perto. (MATURANA; VARELA, 1995, p. 258).

A complexidade suscitou uma nova filosofia da Natureza que, evitando logicamente um retorno ao pensamento mágico ou mecanicista, pauta-se por dois pressupostos fundamentais: de que o ser humano pode estudar a natureza por meio das ciências e a natureza não pode ser concebida fora de sua relação com o ser humano. Além disso, a nova visão pressupõe que os fenômenos antropológicos e sociais não podem obedecer a conceitos gerais menos complexos do que os que fenômenos naturais exigem (NICOLESCU, 1999).

${ }^{3}$ Relatada na Internet por Joy Murray e realizada entre os dias 7 e 9 de agosto de 1993. 
No entanto, como vimos, a complexidade enfrenta alguns sérios contratempos inerentes à sua própria natureza problematizadora (MORIN, 1995, p. 21). Para superá-los, precisamos considerar a essência desconstrutiva do ethos do conhecimento contemporâneo, projetando-se para o futuro, o que depende de um empenho questionador, reconhecendo este ethos como o modo mais efetivo de intervenção e de inovação das realidades (DEMO, 1998, p. 17).

Cumpre notar, aliás, que o processo que promove as transformações não é rigorosamente novo. O que parece ser realmente novidade é o ritmo alucinante

Pelo qual as chamadas 'novas tecnologias' se expandiram no último terço deste século, tornando homens e mercadorias descartáveis, num processo cada vez maior, intensificado a partir da crise estrutural de longa duração iniciada no final da década de setenta. (GADELHA, 1998, p. 35).

Essa situação traz consigo a impressão de que tudo se mundializa: "a produção, o produto, o dinheiro, o crédito, a dívida, o consumo, a política e a cultura. Esse conjunto de mundializações, cada qual sustentando, arrastando, ajudando a impor a outra, merece o nome de globalização" (SANTOS, 1997, p. 163). Os limites entre as nações desaparecem, os espaços se grudam e as pessoas já não sabem a que tempo e a que lugar pertencem, submetidas a todas as formas de privação da liberdade que lançam sombras sobre a opulência sem precedentes de um mundo que nega, desse modo, as "liberdades elementares a um grande número de pessoas - talvez até mesmo à maioria" (SANTOS, 1997, p. 163).

Fato é que não é mais possível negar ou evitar o formidável impacto que as novas tecnologias ligadas ao desenvolvimento das redes informacionais estão produzindo nas atividades humanas, não apenas aquelas ligadas à produção e ao trabalho, mas também e principalmente à condição de vida do mundo. O cenário contemporâneo indica que a cosmologia se desvaneceu na penumbra de um atomismo que provocou a hegemonia de uma perspectiva distorcida da natureza e o colapso "da totalidade orgânica da pessoa em relação ao universo" (O'SULLIVAN, 2004, p. 135). Tornamo-nos, então, filhos pródigos em nossa própria casa, a Terra.

À razão formalizada se atribui a possibilidade de conhecer com certeza o mundo social e natural, constituindo-se como o fundamento único, imprescindível e infalível. Essa autoconfiança absoluta da razão instrumental, contudo, não conseguiu, nem de longe, realizar a quimera iluminista do paraíso na Terra. Aldous Huxley (1894-1963), em sua obra-prima "Admirável Mundo Novo" (1932), profetizou, na contramão dessa promessa vã, uma sociedade desumanizada e totalitária produzida por um progresso científico e tecnológico irresponsável. 
A 'utopia negativa' de Huxley (2001), ao expressar esse aspecto de formalização da razão, acaba por transformá-la em estupidez. E a natureza, "despojada de todo valor ou significado intrínseco", e, no processo de sua emancipação, o ser humano, compartilhando o destino do resto do mundo e, como decorrência dos destinos entrelaçados, subjuga o seu semelhante ao dominar a natureza, que tem sua língua arrancada. E quanto mais a natureza é tratada como mero objeto em relação aos sujeitos humanos, "[...] mais o outrora presumivelmente autônomo sujeito é esvaziado de qualquer conteúdo, até tornar-se finalmente um mero nome sem nada a dominar". E assim, como irracionalidade racionalizada, a civilização passa a integrar "a revolta da natureza como outro meio ou instrumento" (HORKHEIMER, 2003, p. 103-105).

Todavia, a sensibilidade à complexidade pode nos ajudar a tomar consciência de que as relações fundamentais do ser humano "com a vida, com a natureza, com o outro e com o cosmo" dependem da sua maneira de pensar, aprender e conhecer, enfim, da sua "maneira de ser e estar no mundo" (MORAES, 2004, p. 272).

O pensamento complexo pode nos ajudar igualmente a conciliar a reflexão com a sensibilidade e a razão com a experiência ao construir a "afinidade do ser com o ser", não exclusivo do ser humano, mas, como coloca Chardin (1986), como "uma propriedade geral da Vida". Ela vincula, reúne, integra, identifica e prende todos os seres na Terra por meio de uma 'vibração fundamental' que impele a humanidade inexoravelmente para a Unidade, "no Sentido do Universo, Sentido do Todo" (CHARDIN, 1986, p. 301).

Cabe, pois, à educação ajudar a desenvolver a capacidade de lidar com a avalanche de informações que incidem sobre nós cotidianamente, instrumentalizando-nos para buscá-las, selecioná-las, organizá-las e contextualizá-las para, enfim, torná-las significativas.

\section{Os desafios da educação em um mundo em transformação}

A educação, direito inalienável de cidadania, é um dos componentes fundamentais da condição humana e integra o conjunto das disposições sociais que, junto com os direitos civis, constituem os meios para o desenvolvimento que todo ser humano, sem qualquer exclusão, merece desfrutar na condição de cidadão global.

É preciso, porém, deixar muito clara a idéia de desenvolvimento, utilizada aqui no sentido de negar e denunciar determinadas visões que a reduzem ao aumento ou acúmulo de receita monetária ou rendimento financeiro de indivíduos e instituições, de crescimento do Produto Interno Bruto, ou ainda à elevação nos índices de produtividade comercial e industrial e ao 
progresso tecnológico. Nesse caso, o sentido é o da eficiência e da produtividade operacional e regulatória do setor público e o do estímulo à produção, consumo e competitividade do setor privado.

Segundo nossa perspectiva, desenvolvimento é muito mais do que a idéia de 'crescimento econômico sustentado', no cenário atual de crise que viu emergir novos modos de produção, novas formas de organização do trabalho humano e de poder e novos e mais graves problemas. Em oposição a essa concepção, entendemos desenvolvimento como o processo de superação das contradições sociais mediante a expansão das liberdades substantivas e reais de cada ser humano, o que implica a criação de formas de solidariedade internacional apoiadas por um pensar e um agir global e duradouro - sempre no sentido da sustentabilidade, que adota como princípios organizadores o respeito à vida e a preservação do meio ambiente - e não mais apenas em nível local e imediato, levando-se em conta a nova cartografia desenhada por uma cidadania global.

Seria no mínimo ingênuo imaginar que a escola permaneceria incólume, "atingida de frente pela midiamorfose (explosão dos meios de comunicação) e a mudança de paradigma entre analítico e sistêmico. É a razão pela qual é essencial colocar em prática, imediatamente, uma reconfiguração da escola" (ROSNAY, 1997, p. 363).

Partindo da premissa que transformação é a regra, Doll Junior (2002) propõe um novo modelo de currículo em que a linearidade, a mensuração e o determinismo sejam substituídos pela interação, desequilíbrio e conseqüente equilibração. Sugere um currículo modelado em uma matriz em permanente construção que emerge na ação e interação dos participantes, com vários pontos de intersecção e uma rede relacionada de significado.

Subjacente a essa idéia de currículo, situa-se o conceito de autoorganização que postula que as perturbações podem atuar como mola propulsora para reajustamento e redesenvolvimento. Salienta ainda Doll que esses desequilíbrios podem operar de forma positiva, em especial, quando

a atmosfera ou estrutura em que elas são percebidas é suficientemente confortável para que o sujeito não se sinta pressionado a ter sucesso rapidamente, quando nesta atmosfera os detalhes da anomalia podem ser estudados (pode-se inclusive brincar com eles), e quando o tempo (como um fator desenvolvimental) é suficientemente longo para permitir a emergência de uma nova estrutura. (DOLL JUNIOR, 2002, p. 182).

Um dos desafios é que a escola tenha um currículo mais flexível que possibilite o aluno a continuar autônoma e permanentemente o processo de aprendizagem. Nessa linha, o Relatório para a UNESCO, da Comissão Internacional sobre a Educação para o século XXI, adverte-nos de que, 
considerando o volume de informações que circulam atualmente em rede, a capacidade "de se orientar no meio dos saberes tornou-se um pré-requisito do próprio saber, e necessita daquilo que alguns já chamam "nova alfabetização" e que "a capacidade individual de ter acesso e de tratar a informação vai ser um fator determinante para a integração da pessoa, não só no mundo do trabalho, mas também no seu ambiente social e cultural" (DELORS et al., 1998, p. 190-192).

Nesse relatório, estabelece-se que o aprender a ser, a fazer, a viver juntos e a conhecer constituem os pilares fundamentais da educação contemporânea, devendo estar no cerne da política educacional de todos os países.

Na mesma linha de raciocínio, Morin (2000) propõe sete saberes fundamentais, com os quais toda sociedade, mas em especial a escola, deveria trabalhar: as cegueiras paradigmáticas, o conhecimento pertinente, o ensino da condição humana, o ensino das incertezas, a identidade terrena, o ensino da compreensão humana e a ética do gênero humano.

Igualmente em busca de uma síntese, Reboul (2000, p. 81), ao se questionar o que vale a pena ensinar na escola atual, assegura que ensinar o que é exigido pela produção econômica é secundário, visto que, se fosse o primeiro, o ser humano estaria sujeito à máquina econômica e constituir-se-ia, então, em mero "instrumento do instrumento, não um adulto livre e responsável". Nessa perspectiva, propõe que vale a pensa ensinar o que une e o que liberta. O sentido da união é o que integra cada indivíduo de forma duradoura em uma comunidade tão vasta quanto possível. O segundo critério, a liberdade, é o que permite expressar e pensar-se por si mesmo, libertandonos do senso comum e preconceitos.

Não resta dúvida, pois, de que a capacidade para manusear a informação é crucial para se viver em um mundo em constante transformação e deve também abranger o "conhecer-se e saber que se sabe, ações que constituem a essência da ética, que, por sua função reflexiva, interpreta, perscruta, compara, pondera e integra a razão com sensibilidade e equilíbrio" (GASQUE; TESCAROLO, 2004, p. 38). Como auto-apropriação, isso torna-nos aptos às mais diversas atividades do espírito humano, como "abstração, lógica, opções e invenções ponderadas, matemáticas, arte, percepção calculada do espaço e da duração, ansiedades e sonhos de amor" (CHARDIN, 1986, p. 186).

\section{Ética e educação: a viabilização de um mundo novo}

Para que a escola dê conta de todas as transformações, é necessário, inicialmente, conceber o currículo como instrumento que transcende o conjunto 
dos conteúdos a ensinar e a aprender. Primeiramente, porque se reconhece que, atualmente, a educação não se limita à instrução e transmissão de saberes apresentados como verdades únicas e imutáveis trabalhados em uma perspectiva linear e convergente. Ao contrário, a escola deve educar e formar levando-se em conta a rapidez da produção e a veracidade relativa dos novos conhecimentos, a facilidade de acesso à informação por parte dos alunos e as situações e fatos que ocorrem em seu cotidiano ou entorno escolar que geram aprendizagens. Em segundo lugar, reconhece-se, do mesmo modo, que a educação deve integrar as dimensões afetivas, os saberes do fazer, ser e conviver ao conhecer. E, por fim, considera-se que os conteúdos são significativos e contextualizados para quem aprende desde que se baseiem no princípio de que as aprendizagens nascem da experiência prévia dos alunos (LEITE, 2001). $\mathrm{E}$, mais, que esse currículo seja permeado pela ética de forma mais ampla, isto é, em uma perspectiva planetária, para que a humanidade entenda, como assegura Morin (2001), que somos parte da teia da vida e responsáveis por desenvolver uma nova base para políticas ecológicas que nos permitam sobreviver, construir e sustentar comunidades sem colocar em risco as oportunidades para futuras gerações.

Os Parâmetros Curriculares Nacionais para o Ensino Fundamental (BRASIL, 1998) propõem que a escola aborde a ética como tema transversal crucial para a formação da cidadania, uma vez que ela perpassa todas as disciplinas. No supracitado documento, sugere-se tratá-la a partir da discussão dos princípios e não de 'receitas prontas' com os objetivos de compreender o conceito de justiça; respeitar as diferenças; adotar atitudes de solidariedade, colaboração e repúdio às injustiças e discriminação; aplicar os conhecimentos aprendidos na construção de uma sociedade democrática e solidária; construir uma imagem positiva de si; assumir posições segundo seu próprio juízo de valor considerando vários pontos de vistas. A despeito da abrangência e relevância desses objetivos, o documento ainda não trata com o devido destaque a grave e urgente questão do desenvolvimento sustentável em nível planetário.

Todos os indicadores disponíveis hoje no mundo advertem-nos que a sobrevivência do ser humano na terra depende de uma profunda mudança da mentalidade humana, visto que existe uma interligação ecológica de todos os eventos que ocorrem na Terra e da qual fazemos parte. E que nós, tal qual somos hoje, estamos vinculados às condições terrenas. Portanto, tal mudança de mentalidade somente poderá ocorrer se houver alterações em nossa postura ética, tanto em relação a nós próprios quanto em relação ao meio ambiente.

Por conseguinte, é urgente que a escola se coloque no centro desse movimento inexorável de transformação que afeta o mundo hoje, contribuindo para se construir a cultura da nova racionalidade, reconhecer os novos e gravíssimos problemas que atingem a existência do planeta e a vida como um 
todo. Entretanto, a dificuldade no reconhecimento e na assimilação de um novo conjunto de significados não deve nos surpreender, pois reflete a resistência comum do ser humano a processos de mudança que os atingem intrinsecamente.

As exigências do mundo contemporâneo condicionam que ofereçamos aos alunos aquelas capacidades que possibilitem o desenvolvimento de conhecimentos, habilidades e atitudes que, por sua vez, permitam sua adaptação e permanência no mercado de trabalho, bem como sua formação como cidadãos capazes de uma ação efetiva para a construção de uma sociedade justa e solidária e um desenvolvimento sustentável.

Sem dúvida, é preciso discernir que, além de aceitar que o conhecimento é a grande riqueza do mundo contemporâneo, também "é um dos lugares em que a solidariedade entre os homens pode ter mais sentido, um dos elos mais fortes entre os membros de nossa espécie". Afinal, as "árvores do conhecimento tornam este elo visível, palpável [e] encarnam esta solidariedade" (LÉVY; AUTHIER, 1995, p. 25).

Ainda mais do que isso, devemos nos dobrar à evidência de que "no cerne das dificuldades do homem moderno está seu desconhecimento do conhecer, [pois] é o conhecimento do conhecimento que nos compromete". Se concordamos que todo o ato humano ocorre na linguagem e que todo "ato na linguagem produz o mundo que se cria com outros no ato de convivência que dá origem ao humano", então "todo ato humano é, em última análise, o fundamento de toda ética como reflexão sobre a legitimidade da presença do outro" (MATURANA; VARELA,1995, p. 263).

De fato, estamos "fadados à interação, à troca. Temos de nos adaptar, regular nossas necessidades e possibilidades de sobrevivência ao que está fora de nós. E que, mesmo o que está dentro de nós, está sempre em outro lugar" (MACEDO, 1994, p. 1).

Essa ética nos possibilitará transformar o conhecimento em substância da ação humana, sendo a sua ignorância o que deflagra boa parte dos problemas do mundo (MATURANA; VARELA, 1995, p. 265). E será ela igualmente que superará a concepção da escola como um sistema mecânico eficientemente empenhado no treinamento e na domesticação de 'recursos' humanos, na exacerbação do consumo e na ampliação de expropriados, resultado de uma sociedade em que a abolição das contradições e a universalização de uma vida digna continua um desejo distante de ser realizado. A situação de expropriação, como fenômeno contemporâneo, é resultado de uma acumulação de riquezas que não levou à sua redistribuição, como ainda pregam aqueles que utilizam o dinheiro como a medida de tudo, "mas realimentaram o processo de gerar mais expropriações, maior produtividade e mais apropriações" (ARENDT, 2001, p. 267). 


\section{Conclusão}

Educação, portanto, deve 'ocupar' a vida, confundir-se com ela e impregnar-se dela. Educação é, sim, a própria vida vivida em sua plenitude de paz e harmonia, e não apenas um agregado de procedimentos e técnicas que 'preparam' para uma vida produtiva.

Dessa forma, é urgente que se desenvolva em todas as instâncias da sociedade - e aqui colocamos em destaque a escola - uma ética que se empenhe pela integridade da "realidade sagrada primordial" do universo (O'SULLIVAN, 2004, p. 379), estabelecendo um novo contrato de solidariedade em favor da Terra, da vida e da humanidade.

Para tanto, precisamos assumir a "ética dialogada da responsabilidade" que promova os "equilíbrios adequados entre a eficácia e a equidade" e voltada sempre "para o respeito de indivíduo e do bem coletivo, presente e futuro, liberdade e solidariedade" (LIPOVETSKY, 1994, p. 23). Não obstante as ações que promoveram a desagregação da humanidade e a destruição da natureza, portanto, vislumbra-se um "movimento de mundialização associativa e comunitária" (COMPARATO, 2006, p. 433) no qual a escola deve se inscrever incontinenti.

E é essa utopia que abre "passagem para o possível, no sentido oposto a uma aquiescência passiva do estado presente real das coisas" (CASSIRER, 1994, p. 104). Pois é o sentido da utopia de um mundo inédito, mas viável, que nos revela essa possibilidade de um mundo possível de paz, desenvolvimento integral e solidariedade que seja capaz de superar as situaçõeslimites em que a humanidade e o planeta se encontram (FREIRE, 1992, p. 205).

\section{Referências}

ARENDT, Hannah. A condição humana. Tradução de Roberto Raposo. Pósfacio de Celso Lafer. 10. ed. Rio de Janeiro: Forense, 2001.

BRASIL. Ministério da Educação e do Desporto. Secretaria de Educação Fundamental. Parâmetros Curriculares Nacionais. Temas transversais: ética. Brasília: MEC/SEF, 1998.

CASSIRER, Ernst. O mito do Estado [1946]. Tradução de Álvaro Cabral. Rio de Janeiro: Zahar, 1976. 
Ensaio sobre o homem: introdução a uma filosofia da cultura humana [1944]. Coleção Tópicos. Tradução de Tomás Rosa Bueno. São Paulo: Martins Fontes, 1994.

CHARDIN, Teilhard de. 0 fenômeno humano. 6. ed. São Paulo: Cultrix, 1986.

COMPARATO, Fábio Konder. Ética: Direito, moral e religião no mundo moderno. São Paulo: Companhia das Letras, 2006.

DELORS, Jacques et al. Educação, um tesouro a descobrir. Relatório para a Unesco da Comissão Internacional sobre Educação para o Século XXI. São Paulo: Cortez, 1998.

DEMO, Pedro. Conhecimento moderno: sobre a ética e intervenção do conhecimento. Petrópolis: Vozes, 1998.

DOLLJUNIOR, William E. Currículo: uma perspectiva pós-moderna. Porto Alegre: Artmed, 2002.

FOUCAULT, Michel. A hermenêutica do sujeito. São Paulo: Martins Fontes, 2004.

FREIRE, Paulo. Pedagogia da esperança: um reencontro com a pedagogia do oprimido. Rio de Janeiro: Paz e Terra, 1992.

GADELHA, Regina Maria d'Aquino Fonseca. Impactos da Globalização nos Projetos das Elites Nacionais. In: Globalização, a vaca louca do capitalismo Avançado, Revista Cultura Vozes, Petrópolis: Vozes, v. 92, n. 1, 1998.

GASQUE, Kelley Cristine Gonçalves Dias; TESCAROLO, Ricardo. Sociedade da aprendizagem: informação, reflexão e ética. Ciência da Informação, Brasília, v. 33, n. 3, p. 35-40, 2004. Disponível em: <http://www.ibict.br/cionline/ viewarticle.php?id=631>. Acesso em: 4 fev. 2006.

HORKHEIMER, Max. Eclipse da razão. 5. ed. São Paulo: Centauro, 2003.

HUXIEY, Aldous. Admirável mundo novo. São Paulo: Globo, 2001.

JONAS, Hans. O princípio vida. Fundamentos para uma biologia filosófica. Petrópolis: Vozes, 2004.

LEITE, Carlinda. Reorganização curricular do ensino básico: problemas, oportunidades e desafios - Encontros de Primavera, ASA, Porto, 19 e 20 de Abril de 2001. Disponível em: <http://www.fpce.up.pt/ciie/publs/artigos/ asa.doc>. Acesso em: 5 out. 2006. 
LÉVY, Pierre; AUTHIER, Michel. As árvores do conhecimento. São Paulo: Escuta, 1995.

LIPOVETSKY, Gilles. O crepúsculo do dever: a ética indolor dos novos tempos. Tradução de Fátima Gaspar e Carlos Gaspar. Lisboa: Dom Quixote, 1994.

MACEDO, Lino de. Ensaios construtivistas. São Paulo: Casa do Psicólogo, 1994.

MATURANA, H.; VARELA, F. A árvore do conhecimento. Campinas: Psy, 1995.

MORAES, Maria Cândida. Pensamento eco-sistêmico: Educação, aprendizagem e cidadania no século XXI. Petrópolis: Vozes, 2004.

MORIN, Edgar. Introdução ao pensamento complexo: Epistemologia e Sociedade. Lisboa: Instituto Piaget, 1995.

Os sete saberes necessários à educação do futuro. 2. ed. São Paulo: Cortez, 2000.

A religação dos saberes: o desafio do século XXI. Jornadas temáticas idealizadas e dirigidas por Edgar Morin. Tradução e notas de Flávia Nascimento. Rio de Janeiro: Bertrand Brasil, 2001.

NICOLESCU, B. Aspectos Gödelianos da natureza e do conhecimento. Disponível em: $<$ http://www.cetrans.futuro.usp.br/godelianos.htm $>$. Acesso em: 1999 .

O'SUlLIVAN, Edmund. Aprendizagem transformadora: Uma visão educacional para o século XXI. São Paulo: Instituto Paulo Freire, 2004.

REBOUL, Olivier. A filosofia da educação. Lisboa: Edições 70, 2000.

ROSNAY, Joël de. 0 homem simbiótico: Perspectivas para o terceiro milênio. Petrópolis: Vozes, 1997.

SANTOS, Milton. A natureza do espaço: técnica e tempo; razão e emoção. 2. ed. São Paulo: Hacitec, 1997.

SCHNITMAN, Dora et al. Novos paradigmas, cultura e subjetividade. Tradução. Jussara Haubert Rodrigues. Porto Alegre: Artmed, 1996.

LITTLEJOHN, Stephen (Org.). Novos paradigmas em mediação. Tradução de Jussara Haubert Rodrigues e Marcos A. G. Rodrigues. Porto Alegre: Artmed, 1999. 
TARNAS, Richard. A epopéia do pensamento ocidental: Para compreender as idéias que moldaram nossa visão de mundo. 7. ed. Rio de Janeiro: Bertrand Brasil, 2005.

VASCONCEllos, Maria José Esteves. Pensamento sistêmico: o novo paradigma da ciência. Campinas: Papirus, 2003.

Recebido: 04 de abril de 2007

Aceito: 17 de agosto de 2007 